\title{
Obregón y Carranza: personalidad en el desenlace de la Revolución mexicana*
}

\author{
Linda B. Hall
}

$\boldsymbol{P}$ ara cuando la fase militar de la Revolución mexicana llegó a su fin en los años de 1916 y 1917, dos de los dirigentes ya habían afirmado su preponderancia. Se trataba de Venustiano Carranza, primer jefe de la Revolución constitucionalista, y de Alvaro Obregón, su secretario de guerra. La relación personal entre estos dos hombres nunca había sido estrecha, aunque la colaboración entre ambos fuera la clave de la victoria de los constitucionalistas sobre los convencionistas que encabezaba Pancho Villa. Además, la naturaleza de tal colaboración había influido profundamente en la fase militar de la Revolución y habría de influir en la época de institucionalización que le siguió. Sin embargo, surgen dos grandes interrogantes: ¿por qué permaneció Obregón al lado de Carranza, a pesar de que este último había intentado debilitarlo? y ipor qué Carranza no pudo reconocer la aplastante popularidad de Obregón en 1920 y se negó a permitir que le sucediera como presidente de México? Probablemente hayan influido algunas consideraciones politicas en la primera de estas cuestiones, pero la segunda fue claramente un error de juicio que llevó a Carranza al fracaso y a la muerte. Este ensayo propone como tesis que las personalidades de ambos tuvieron profunda importancia en la toma de decisiones y que un estudio de dichas personalidades, haciendo a un lado cuestiones como la conveniencia política y la ideología, será provechoso para entender la relación que se dio entre estos dos hombres y, de ahí, la secuencia de acontecimientos que llevaron al propio Obregón a asumir la presidencia. Por lo tanto, me concentraré en esa relación desde el punto de vista de la personalidad, más que desde el punto de vista de la política o de la ideología.

Debemos tener en cuenta que la personalidad opera dentro de un contexto histórico y que es solamente uno de los muchos factores que influyen en los sucesos históricos. Así, este trabajo explorará la relación entre estos dos hombres - ambos dirigentes revolucionarios, ambos con una enorme e intensa motivación - y la manera en que tal relación afectó a, y se vio afectada por sucesos de importancia histórica. Según ha anotado John Mack en su estudio sobre Lawrence de Arabia, la personalidad debe ser considerada solamente como una parte del “juego dinámico entre... los impulsos internos y los propósitos y una serie de oportunidades y realidades políticas, sociales e históricas que coinciden en un momento dado".

En el contexto de la historiografía más reciente, el papel de la personalidad, e incluso el de la misma acción individual, ha sido considerablemente desatendido, mientras que los historiadores se concentran en

\footnotetext{
* Traducción de Lilia Granillo Vázquez.

' John E. Mack, A Prince of our Disorder: The Life of T.E. Lawrence (Boston-Toronto, Little Brown \& Company, 1976), p. XIX.
} 
las estructuras -económicas, sociales y políticas - y en determinar el marco de referencia que estas estructuras imponen a individuos y sucesos. Se ha hecho hincapié en el estudio de tales estructuras en términos cuantificables para dotar asi al estudio de la historia de mayor "ciencia". Sin embargo, al tratar el tema de la personalidad, ingresamos en un campo considerablemente más especulativo y potencialmente más ilustrativo si se aplica a cierta clase de problemas históricos. De ahi que me sienta obligada a definir los términos y a delimitar una base conceptual para el estudio del caso específico que presento a continuación.

Primero que nada, el término personalidad se empleará en un sentido amplio, para designar aquellos atributos psicológicos que, como Fred Greenstein ha observado, "nos llevan a concluir que la gente es... sociable, hostil o flemática --o que tiene otras cualidades personales, tal vez más complejas -". ${ }^{2}$ En resumen, sin recurrir a un psicoanálisis profundo, trataré el comportamiento político de los personajes conforme se vea influido por las características propias de cada personalidad, según se muestre en las acciones que reflejen necesidades internas, predilecciones y motivaciones.

Greenstein ha señalado una serie de situaciones en las que la personalidad se vuelve particularmente relevante para el análisis psicológico. Las situaciones ambiguas destacan porque permiten que las diferencias personales se manifiesten, sea debido a una nueva situación -en la que las indicaciones o las instrucciones a seguir no estén muy claras para la conducta - o sea debido a la complejidad de la situación - en la que las indicaciones que se presenten sean incompatibles o muy diferentes entre sí-. Es obvio que una situación revolucionaria, en la que se han roto las reglas del juego, es especialmente ambigua. Más aún, en el trato entre individuos como Carranza y Obregón, de diferentes antecedentes sociales, de diferentes regiones del país, las indicaciones se vuelven particularmente oscuras. De hecho, el segundo punto que Greenstein señala es que la ausencia de "mentalidad socia!mente uniforme" entre quienes participan en la política, aumenta el potencial de la variabilidad personal. Dos más de las observaciones de este autor parecen ser de particular importancia en el contexto de las relaciones entre Obregón y Carranza. Primero, Greenstein afirma que si uno de los participantes posee una intensa propensión a estar en contra de las sanciones prevalecientes, es más posible que las características personales influyan en el comportamiento. Greenstein se refiere a ello en términos de compulsión y agresión, algo que parece ir de acuerdo con el carácter de nuestros hombres. Segundo, mientras mayor sea la injerencia de lo emocional en la actividad política de un personaje, más probable es que las características personales causen gran efecto en el comportamiento. Es evidente que en el caso de individuos que se ocupan preponderantemente de la actividad revolucionaria, el papel político que desempeñan es esencial para la personalidad, de tal forma que el vínculo entre la estructura de personalidad y acción política es singularmente fuerte. ${ }^{3}$ En una situación revolucionaria - con su caudal de decisiones espontáneas, dentro de un contexto en constante cambio- el vínculo entre personalidad y acción alcanza gran libertad para obrar. Además, un puesto de dirección también proporciona el poder que puede transformar

2 Fred Greenstein, Personality and Politics Chicago, Markham Publishing Company, 1969 , p. 6.

${ }^{3}$ Greenstein, op. cit., p. 50-54. 
las decisiones personales en acontecimientos. Todos estos factores confieren relevancia a las personalidades de Obregón y Carranza en los sucesos de la Revolución mexicana.

Carranzá sobresalió durante el periodo de Porfirio Díaz, mismo que llega a su fin con la Revolución, y durante el cual ocupó los cargos de senador y gobernador de Coahuila. ${ }^{4}$ Era 21 años mayor que Obregón y mucho más seguro que éste, social y económicamente. Hacendado en su estado natal, Coahuila, su primera actividad revolucionaria parece estar dirigida más bien en contra del dictador Díaz que en favor de cualquier cambio revolucionario de gran alcance, que favoreciera a las masas. Había ingresado a la Revolución desde sus inicios, como subalterno de otro terrateniente coahuilense, Francisco I. Madero, de cuyo gabinete revolucionario formó parte, siendo más tarde gobernador de Coahuila durante la presidencia de Madero.

Obregón, por su parte, tenía unos antecedentes mucho más complicados. Apenas conoció a su padre, que murió siendo él aún muy pequeño pues era el menor de 18 hermanos. Fue criado por la madre y, particularmente, por tres hermanas, todas mucho mayores que él. Además, la familia había sido de posición acomodada a mediados del siglo XIX, pero perdió sus posesiones debido a problemas políticos (sobre todo por su adhesión al Imperio de Maximiliano, al que puso fin Ben ito Juárez), a unas inundaciones y a los ataques de tos yaquis. Cuando Obregón nació, su padre trabajaba de jornalero en Alamos. No obstante, la familia todavía conservaba relaciones con la elite sonorense, sobre todo por los Salido, la familia materna. ${ }^{5}$ Los principales compañeros de juego de Obregón fueron los indios mayos que vivían cerca dc su casa, en Huatabampo. Creció por lo tanto, totalmente bilingüe. Se trataba de un muchacho prometedor y de gran iniciativa: emprendió pequeños negocios, entre ellos, una compañia cigarrera a los 13 años de edad, y desempeñó trabajos ocasionales, sobre todo como mecánico. Las relaciones de la familia le ayudaban a encontrar trabajo, mas siempre le tocaba hacer el papel del pariente pobre, con todas las humillaciones que esto implicaba. Asi, infancia y juventud quedaron pobladas de situaciones ambiguas: era bilingüe y estaba compenetrado de las dos culturas; aunque carecia de dinero creía tener cierto derecho a una posición social superior; huérfano de padre, poseía en cambio una familia numerosa, estaba rodeado de muchos hermanos y hermanas mayores (en ocasiones demasiado mayores) que recordaban haber vivido tiempos mejores y de una madre que, en cierto sentido, se había casado con alguien inferior a ella, lo cual lamentó cuando al marido se le acabó la fortuna. ${ }^{6}$ No es sorprendente que Obregón haya resultado ser de gran empuje y muy ambicioso.

Inesper’adamente, sin embargo, fue Carranza, más que Obregón, quien estuvo dispuesto a desafiar a la autoridad establecida. Carranza

4 James Cockcroft, Intellectual Precursors of the Mexican Revolution, 1900-1913, Austin y Londres, The University of Texas Press, 1968, p. 60.

5 Harold Lasswell ha señalado el potencial revolucionario de los hombres cuyas familias han perdido las riquezas y la posición social y ha hecho hincapié en la importancia de los casos en los cuales la madre ha sobrevivido para transmitir la expectativa de recuperación a su hijo. Cf. Harold D. Lasswell, "The Political Personality", reimpreso en Personality and Politics, editado por Gordon J. DiRenzo Garden City, Anchor Books, 1974, p. 42.

- Cf. Linda B. Hall, Alvaro Obregón: Power and Revolution in Mexico, 1911-1920, College Station. Texas A \& M Press, 1981. 
se habia abierto, literalmente, paso a la fuerza, hasta llegar a las posiciones que ocupó durante el gobierno de Díaz y, a la postre, se unió al movimiento de Madero en contra del régimen porfiriano. Obregón no inició, en ninguna ocasión, movimiento alguno contra la autoridad establecida. Comenzó la carrera militar en el intento de sofocar una revuelta contra Madero, entonces presidente electo de México; sus esfuerzos posteriores estuvieron dirigidos a derrocar al hombre cuyo poder consideraba ilegítimo: Victoriano Huerta. En esta lucha, Obregón se subordinó a Carranza, que había sido gobernador de Coahuila y que dirigía el movimiento para vengar a Madero. Pese a los muchos problemas que hubo entre Obregón y Carranza desde los primeros dias de su colaboración, Obregón no se levantó en contra del primer jefe de los constitucionalistas sino hasta 1920 . Nunca negó la legitimidad del poder de Carranza como primer jefe de la Revolución ni como presidente de México. Después de la Convención Militar de Aguascalientes, permaneció junto a Carranza a pesar de no contar con su cooperación. Incluso en los tiempos de la Convención Constituyente, cuando la ruptura entre ellos era alentada por sus respectivos seguidores, Obregón, entonces secretario de guerra, no hizo ningún movimiento que amenazara a Carranza. A la larga, renunció al gabinete carrancista, pero sin desafiar abiertamente la autoridad del presidente. Sólo durante la campaña de 1920, cuando se encontraba en la ciudad de México bajo la vigilancia de los agentes carrancistas, y momentáneamente sujeto a arresto domiciliario, se unió al movimiento de Agua Prieta para derrocar a Carranza. Aun en aquella ocasión, no fue él quien inició el desafío militar. Por el contrario, se encontraba atrapado en la ciudad de México cuando Adolfo de la Huerta y Plutarco Elías Calles, desde lo que podría calificarse de refugio, la lejana región de Sonora, se declararon en contra de Carranza. Tanto respeto por la autoridad en un hombre que era particularmente ambicioso merece ser examinado. Me parece que tal vez haya reconocido en la figura digna de Carranza a una autoridad de la que, como huérfano, había carecido. Y que acaso su propia carrera política, hasta abril de 1920, hubiera sido un esfuerzo constante por establecerse como el evidente sucesor legitimo de Carranza, como el hijo que, aunque no hubiera sido amado, sí hubiese merecido ser el heredero. Parece que hubiera estado tratando de convertirse en el legítimo sucesor ante los ojos de Carranza, ante los del pueblo de México y ante los suyos. Por consiguiente, desafió a Carranza mediante la presión de una campaña política emprendida a lo largo de todo el país en 1920; mediante la popularidad que ganó como general al haber derrotado a Francisco Villa; mediante las negociaciones con varios grupos politicos y mediante su entendimiento con el Partido Liberal Constitucionalista y el apoyo que recibiera de este partido (que, de 1917 a 1920 siempre estuvo en desacuerdo con Carranza). No obstante, nunca pudo resignarse a efectuar abiertamente una rebelión militar. Al parecer, era imposible que se diera cuenta de que Carranza nunca lo iba a reconocer como sucesor, pues él mismo necesitaba ese reconocimiento.

Por otro lado, Carranza era igualmente intransigente en cuanto a la posibilidad de que Obregón lo sucediera en la presidencia. Nuevamente, por razones que se antojan de personalidad, más que de política, Obregón era totalmente inaceptable para Carranza. El primer jefe de la Revolución era un hombre severo, digno, inflexible en sus principios. Consideraba que ciertos rasgos de Obregón, como la alegría de vivir (entre los oficiales revolucionarios, eran famosas las fiestas que las tro- 
pas sonorenses organizaban entre batalla y batalla); la manera informal con que solia tratar a gente de cualquier clase social y que se manifestaba en la franqueza de sus relaciones con la tropa y su sinceridad en las negociaciones y los acuerdos, eran muestras de titubeo y de falta de propósitos sólidos, tan necesarios en un futuro presidente de México. Según Carranza, al acercarse el término de su mandato, confió a Bernardo Mena Brito, Obregón carecía de principios, "siempre repite de memoria las ideas del último con el que ha hablado". Además, Carranza pensaba que sería desastroso que Obregón llegara a presidente ya que "no tiene un plan preconcebido, ni entiende los problemas nacionales; tampoco posee las virtudes que son más necesarias para gobernar. En un momento de entusiasmo o de necesidad, seria capaz de entregar el país entero a los Estados Unidos para satisfacer su codicia o su ambición".?

Esta diferencia entre los dos hombres se manifestó más claramente en el campo de las negociaciones. Desde los tiempos de los tratados de Teoloyucan de agosto de 1913, cuando Obregón aceptó la rendición de las fuerzas federales a nombre del primer jefe, Carranza acostumbraba dejar las negociaciones en manos de Obregón. Sin embargo, los dos tenían actitudes muy diferentes en torno a estos asuntos, lo cual provocaba continuos problemas entre ellos, lo que finalmente ocasionó la renuncia de Obregón al gabinete de Carranza. Para Carranza el objetivo de las negociaciones era únicamente obtener lo que quería, tanto en su calidad de primer jefe como cuando era presidente de México. En esencia, no estaba dispuesto a negociar nada.

Su tendencia era más bien la de imponer los términos. Por otra parte, Obregón era magistral en tales cuestiones, conciliador nato de facciones en pugna. Podía hacer sentir a las persónas y a los grupos que se habían alcanzado objetivos importantes a pesar de que entre ellos existieran verdaderas diferencias. Era un maestro de la mediación, función que él y sus sucesores habrian de establecer como parte importante del oficio de ser presidente, en los años posteriores a 1920. Además, estaba dispuesto a considerar todo a la larga y en perspectiva y a hacer concesiones en lo inmediato a fin de que se cumplieran objetivos parciales. No obstante, Carranza juzgaba esta disposición como falta de principios y tendencia a la traición.

Los problemas no surgieron en Teoloyucan, pues las fuerzas federales estaban indudablemente derrotadas; su presidente, Victoriano Huerta, ya había abandonado el país. Dichas fuerzas estaban dispuestas a aceptar los términos de Carranza. Sin embargo, cuando los generales revolucionarios se reunieron en la Convención Militar de Aguascalientes, Carranza se negó a aceptar las concesiones que Obregón había establecido de acuerdo con las diferentes facciones. Particularmente, se negó a pactar en favor de Eulalio Gutiérrez, el presidente de la Convención, recientemente electo. Consideró la adhesión de Obregón a Gutiérrez (en efecto su promotor) como una traición, a pesar de que, de hecho, no existía ninguna otra posibilidad para conciliar su propio respaldo político con los de Villa y Zapata, caudillo de las otras dos grandes facciones revolucionarias. Al parecer, Carranza estaba en lo cierto al juzgar que no había posibilidades de transigir con los villistas y que cualquier concesión habría sido considerada simplemente como

7 Bernardo Mena Brito, Ocho diálogos con Carranza, 2a. ed., México. 
una flaqueza. En todo caso, estimó que los intentos de pactar de Obregón eran desleales y que parecían titubeos. Efectivamente, lo desautorizó como su representante. ${ }^{8}$ A unque Obregón volvió a ponerse del lado de Carranza y encabezó a los carrancistas en la victoriosa batalla que en última instancia significó la derrota de Villa, Carranza no volvió a confiar en él nunca más y únicamente lo hacía cuando se veía obligado. Si bien deseaba utilizarlo como caudillo militar, hizo todo lo posible para evitar que se convirtiera en un poder político.

Una muestra más sorprendente de la diferencia de actitudes se dio en ocasión de las negociaciones de Obregón con los Estados Unidos. Se trataba de un intento de finalizar con la intervención de Pershing en México en 1916. Tras pláticas exhaustivas con el general Hugh L. Scott, Obregón llegó a un acuerdo sólo para que Carranza lo rechazara, por considerar que era una entrega a los Estados Unidos. En realidad es muy posible que Carranza, con toda intención, haya enviado a Obregón a una misión tan difícil, para así dejarlo políticamente marcado como proclive a los estadunidenses. Mientras tanto, Carranza rechazaba o ignoraba los propósitos politicos de Obregón en otras áreas. Carranza reconocía la eficacia militar de Obregón. La necesidad de controlar las incursiones de Villa en la frontera y de evitar la intervención de los Estados Unidos en la situación mexicana había obligado finalmente a Carranza a nombrar a Obregón como secretario de guerra. ${ }^{9}$ No obstante, la aversión personal y la desconfianza le impidieron reconocer el agudo criterio político que Obregón poseía. ${ }^{10}$

Un problema más en relación con sus personalidades surgió entre los dos debido a la diferencia de actitudes hacia las tropas y los ciudadanos que los seguían. Obregón mantenía una actitud abierta. Cuando viajaba con las tropas, se mezclaba con su gente por las noches, departiendo con ellos antes y después de cada batalla. El vagón de ferrocarril que ocupaba estaba siempre abierto a los ciudadanos de las regiones que recorría, quienes acudían a hablar con él. Más aún, poseía una memoria extraordinaria para los nombres, podía saludar con familiaridad a personas que sólo había visto una o dos veces. También podía hacerles creer a aquéllos con quienes conversaba que se interesaba verdaderamente en lo que ellos decían. Los escuchaba con atención, aunque no estuviera de acuerdo." Todo ello difería de la actitud de Carranza. El primer jefe rehuía la lucha, no encabezaba las tropas en las batallas, era muy reservado, accesible solamente para sus más cercanos conseje-

8 Para la documentación sobre el último intento de Obregón de mantener unida a la Convención, véase la carta de Obregón a Carranza fechada el ll de noviembre de 1914, Archivo de la Secretaría de Relaciones Exteriores, L-E-841 R, legajo 2.

9 Para información sobre el rechazo de Carranza a las propuestas de Obregón, véanse en Documentos de la Revolución Mexicana, editado por Isidro Fabela México, Editorial Jus, vol. XVI, las siguientes cartas: Carranza a Obregón, 15 de mayo de 1915, p. 140-141; Obregón a Carranza, 11 de septiembre de 1915, p. 226-228; Carranza a Obregón, 29 de septiembre de 1915 p. 240-241; Obregón a Carranza, 6 de diciembre de 1915, p. 270-271. Sobre las negociaciones entre Scott y Obregón veánse: Hugh L. Scott, Some Memories of a Soldier, Nueva York y Londres, The Century Co., 1928, p. 525-527; el escrito de Scott y Funston al secretario de Guerra, Departamento de Estado de los Estados Unidos, en Papers Relating to the Foreign Relations of the United States, 1916, Washington, Government Printing Office, 1925, 538; El Nacional, México, 8 de mayo de 1916, p. 3.

${ }^{10}$ Mena Brito, op. cit., p. 74-75.

"Daniel Cosio Villegas, entrevista, colección de Historia Oral de Columbia. Ignacio Ramos Praslow, entrevista con la autora, 16 de noviembre de 1972. Jesús Romero Flores, entrevista con la autora, 12 de abril de 1973. 
ros. ${ }^{12}$ Esta diferencia de estilos tuvo consecuencias políticas muy serias, ya que mientras Obregón atraía apoyo para el movimiento, Carranza provocaba que se lo retiraran. Un ejemplo muy ilustrativo lo constituye el caso del acercamiento a los líderes laborales en la ciudad de México, en marzo de 1915. Con la ayuda del doctor Atl y de Jesús M. Garza, Obregón había establecido un acuerdo con la Casa del Obrero Mundial: los miembros de los sindicatos obreros se unirian a la lucha contra Villa. Sin embargo, por poco se desintegra el acuerdo cuando los lideres fueron a Veracruz a discutir con Carranza los términos de la cooperación. La hostilidad que Carranza mostró a estas personas ha quedado muy bien documentada. Carranza no deseaba llegar a ningún acuerdo que no fuera aceptar la adhesión total e incondicional del movimiento obrero a su liderato. Las negociaciones casi terminan en este punto. Aunque Carranza finalmente aceptó la ayuda - que seguramente fue decisiva en la lucha contra Villa - en adelante estos hombres encontraron en Obregón a su verdadero dirigente, quien a su vez los aceptó como valiosos compañeros de armas. ${ }^{13}$

Podríamos multiplicar los ejemplos, pero una anécdota puede resultar más instructiva. Durante el primer mes de lucha contra las tropas villistas y zapatistas, luego del fracaso de la Convención Militar de Aguascalientes en noviembre de 1914, la moral de las tropas de las fuerzas carrancistas estaba muy baja debido a que habían sido obligados a retroceder en la línea del ferrocarril de Veracruz. Habían perdido Puebla a manos de los zapatistas el 15 de diciembre. En vista de aquello, Obregón convenció al primer jefe de que se desplazara en tren de Veracruz a Apizaco, Tlaxcala, a fin de infundir ánimos a las tropas a lo largo de la vía. La expedición casi termina en desastre. Los zapatistas habían capturado una pequeña estación desde donde lanzaron una locomotora que iba a estrellarse contra el tren de Carranza. Se evitó un grave accidente cuando el maquinista de Carranza logró disminuir la velocidad y comenzó a retroceder para amortiguar el impacto del choque. Todos los que viajaban con Carranza, incluso Obregón, saltaron del tren cuando aminoraba la marcha, excepto Carranza, quien se preparó para recibir el golpe con dignidad. Sin embargo, su dignidad se resquebrajó cuando, en el vagón, se cayó de la percha una gran águila disecada y le dio un picotazo en la frente. El incidente provocó muchas risas, particularmente de Obregón, de quien algún observador dijo que su "jocosidad era característica". Carranza, cuya jocosidad no era caracteristica, no se rió. ${ }^{14}$ Precisamente durante este periodo, Obregón a pesar de sus continuos éxitos militares en contra de Villa, era ignorado por Carranza como figura política y se fue alejando del presidente. Fue

${ }^{12}$ Para una serie de diversas impresiones sobre Carranza, véase Douglas W. Richmond, "Venustiano Carranza's Rise to Power", Tesis de maestria sin publicar, Universidad de Washington, 1971, p. 3-8. Para el juicio de un observador nada favorable hacia Carranza véase John Reed, Insurgent Mexico, Nueva York, International Publishers, 1969, p. 271-278.

13 Sobre la actitud de Carranza, véase Luis Araiza, Historia del movimiento obrero mexicano, vol. III, México, Editorial Cuauhtémoc, 1964-1965, p. 69 y Rosendo Salazar y José G. Escobedo, Las pugnas de la gleba, vol. I, México, Editorial Avante, 1923, p. 97. Sobre el acercamiento de Obregón al movimiento obrero en la ciudad de México, a través del doctor Atl y de Garza, véanse La Prensa, 8,12,14,15, 16, 19, 21, y 24 de febrero, y 3 de marzo de 1915; y El Pueblo, 9, 13 y 14 de febrero de 1915.

i4 Juan Barragán, Historia del Ejército y de la Revolución Constitucionalista, vol. II, México. Antigua Librería Robredo, 1946, p. 174. 
en este momento cuando Obregón comenzó a buscar una base de apoyo propia entre los campesinos a quienes habia distribuido tierras mientras viajaba; entre los obreros organizados y entre la Confederación Revolucionaria, organización que él, el doctor Atl y otros habían formado con el fin de presionar a Carranźa para que llevara a cabo reformas sociales explícitas y específicas. ${ }^{15}$ Obregón comenzaba a darse cuenta de que Carranza no quería recompensar sus hazañas militares prestando a las ideas políticas obregonistas la atención que les correspondía.

En mi opinión, esta renuencia de Carranza se debió en parte a cuestiones de personalidad y de aversión, una diferencia en el estilo personal que tuvo consecuencias políticas directas. Aunque también hubo razones políticas e ideológicas que provocaron las discrepancias entre los dos caudillos. A la postre, basándose en esta aversión personal, Carranza habria de tomar decisiones políticas que llevarian a Obregón a reunir una amplia base de apoyo entre aquellos grupos revolucionarios que se habian apartado de Carranza: los obreros, el movimiento agrario y, particularmente, los zapatistas, al igual que los incipientes partidos políticos tales como el Partido Liberal Constitucionalista, que comenzaba a formarse con los que salían de las filas de los militares que habian pertenecido al ejército revolucionario y de los ciudadanos que habían acompañado a dicho ejército en sus viajes. Esta coalición de fuerzas de oposición llegaría a ser tan poderosa que, con el tiempo, $\mathrm{Ca}$ rranza trataría de detenerla por la fuerza. Con ello, dio lugar a otra fase militar - muy breve - de la Revolución mexicana y a su propio asesinato, cometido mientras viajaba de nuevo a Veracruz. La personalidad habia llevado a Carranza a cometer políticamente un error de juicio. Error que habría de costarle el apoyo político y, finalmente, la vida.

En lo que respecta a Obregón, no hay duda de que hubiera preferido ser ungido presidente sucesor de Carranza. Al no lograrlo, forjó su propio respaldo político hacia fines de 1919 y principios de 1920 , para tratar de obligar a Carranza a que lo reconociera como heredero politico. Sólo la revuelta franca en Sonora y la certidumbre de que él mismo estaba momentáneamente sujeto a arresto domiciliario pudieron obligarlo a huir para salvar la vida y a proclamarse en contra de Carranza desde el seno de sus nuevos aliados, los zapatistas, en el sur de México.

Así pues, la personalidad en una situación cambiante, revolucionaria, dio lugar a un desenlace revolucionario muy singular. De mala gana, Obregón se vio forzado a abandonar el movimiento carrancista. Se volvió en contra de este movimiento formando una coalición de fuerzas excepcionalmente poderosa entre diversos sectores de la sociedad mexicana, dentro de la cual fungía como mediador. Esta coalición habría de proporcionar una base firme para la institucionalización, lo que a su vez daría lugar a la estabilidad politica extraordinaria que caracteriza a México durante la mayor parte del siglo XX. 